Published in final edited form as:

Cancer Nurs. 2012 September ; 35(5): 347-354. doi:10.1097/NCC.0b013e3182365646.

\title{
Changes in Siblings after the Death of a Child from Cancer
}

\author{
Terrah L. Foster, PhD, RN, CPNP \\ Vanderbilt University, Nashville, TN
}

Mary Jo Gilmer, PhD, MBA, RN, FAAN

Vanderbilt University, Nashville, TN

Kathryn Vannatta, PhD

The Research Institute at Nationwide Children's Hospital

Maru Barrera, PhD

Hospital for Sick Children

Betty Davies, RN, PhD, FAAN

University of California San Francisco

Mary S. Dietrich, PhD

Vanderbilt University, Nashville, TN

Diane L. Fairclough, DrPH

University of Colorado Health Sciences Center

Cynthia A. Gerhardt, PhD

The Research Institute at Nationwide Children's Hospital

\begin{abstract}
Background-Few studies have examined changes in siblings after the death of a brother or sister, particularly from mother, father, and sibling perspectives within the first year post-death.

Objective-This descriptive study identified and assessed the frequency of changes in siblings after a child's death from cancer.

Methods-Participants were recruited from cancer registries at three hospitals in the U.S. and Canada 3-12 months after the child's death. Thirty-six mothers, 24 fathers, and 39 siblings from 40 families were included. Semi-structured interviews using open-ended questions were conducted with each parent and sibling separately in the home. Content analysis identified emerging themes, and McNemar tests compared frequencies between each paired set of reports (sibling vs. mother, sibling vs. father, mother vs. father).
\end{abstract}

Results-Sixty-nine percent of participants reported personal changes in siblings (e.g., changes in personality, school work, goals/life perspective, activities/interests). Forty-seven percent noted changes in siblings' relationships with family members and peers. Only $21 \%$ of participants reported no changes attributed to the death. Comparisons of frequencies across informants were not significant.

Correspondence: Terrah L. Foster, PhD, RN, CPNP, Vanderbilt University School of Nursing, 461 21st Avenue South, 409 Godchaux Hall, Nashville, TN 37240 terrah.L.foster@ vanderbilt.edu).

Conflicts of interest: No authors have any other conflicts of interest to disclose.

Publisher's Disclaimer: This is a PDF file of an unedited manuscript that has been accepted for publication. As a service to our customers we are providing this early version of the manuscript. The manuscript will undergo copyediting, typesetting, and review of the resulting proof before it is published in its final citable form. Please note that during the production process errors may be discovered which could affect the content, and all legal disclaimers that apply to the journal pertain. 
Conclusions-Most siblings experienced changes in multiple areas of their lives after the death of a brother or sister to cancer. Some changes reflected siblings that were positively adapting to the death, while other changes reflected difficulties.

Implications for practice-Our findings offer guidance to improve aftercare for bereaved siblings and their families. Additional research is needed to further delineate the needs of bereaved siblings and to develop strategies to promote adaptation to loss.

Almost $80 \%$ of individuals grow up with a sibling. ${ }^{1}$ Unfortunately, nearly 60000 children under the age of 20 die each year in the United States and Canada, $, 2,3$ leaving behind an estimated 480000 grieving siblings in the past decade. The sibling relationship is a unique, multifaceted, often lifelong bond $\mathrm{d}^{4-6}$ that is important to childhood socialization and development. ${ }^{5,7-8}$ Thus, the death of a brother or sister can have a profound impact on surviving siblings. ${ }^{9}$

While children and adolescents manage changes attributed to normal development, bereaved siblings are simultaneously challenged with stressors associated with the death of a brother or sister. According to the Dual Process Model, ${ }^{10}$ the death can result in siblings alternating between positive and negative aspects of dealing with loss itself and secondary concurrent changes. For some siblings, the death can result in difficulties, while others may experience growth opportunities. Bereaved siblings may have internalizing and externalizing problems. ${ }^{11-14}$ They have reported feeling guilty, anxious, and depressed, ${ }^{14-16}$ and parents have noted similar problems in their children, including anxiety, nightmares, and posttraumatic stress symptoms. ${ }^{17,} 18$ On the other hand, resilient outcomes have included greater maturity, acquiring a new life philosophy, and becoming more compassionate. ${ }^{19-21}$

Bereaved siblings may also experience changes in social functioning and relationships. Compared to normative samples, bereaved siblings have been reported to have significantly lower social competence and higher social withdrawal scores within two years postdeath. ${ }^{11,22}$ Siblings may feel estranged from peers, and ordinary peer activities may seem less important, further isolating them from friends. ${ }^{19,23,24}$ They may receive limited support and communication from parents who are focused on their own grief, ${ }^{25}$ and some children may feel protective of and responsible for their grieving parents. ${ }^{12,}{ }^{19}$ Others experience closer family relationships ${ }^{12,26}$ or describe school, friends, and activities as a "place of refuge." 14

Previous studies of bereaved siblings have used quantitative ${ }^{11,13,21}$ or qualitative approaches, ${ }^{12,14,27-29}$ but few have included both methods e.g., 19 which could enrich our understanding of both challenges and growth. Studies have occurred 2 months to 7 years post-death, ${ }^{12-14,21,27,28}$ but seldom within a year. Sibling outcomes have been examined from parent $>$ perspectives ${ }^{30,31}$ or self-reports, ${ }^{12,14,28,32-34}$ but mothers, fathers, and siblings are rarely included in the same study. ${ }^{19,35}$ This is critical to understanding bereavement within the family context and its impact on siblings' grief experience. Moreover, studies pertaining to sibling bereavement have included various causes of childhood death, including sudden unexpected death, ${ }^{11,17,18,32}$ suicide, ${ }^{19}$ and still born death, ${ }^{31}$, yet little research has examined sibling bereavement related to children with cancer. ${ }^{14,24,26}$ The purpose of this study was to: (a) examine bereaved parents' perceptions of changes in siblings after the death of a brother or sister to cancer, (b) assess siblings' views of changes in themselves, and (c) compare sibling and parent reports.

\section{Methods}

This research was part of a multi-site longitudinal study of families following the death of a child from cancer. In the larger study, data collection involved visits to bereaved siblings' 
schools and homes in the first year after the death, followed by another home visit in the second year post-death. This paper includes cross-sectional, qualitative data collected from a subset of families at the first home visit.

\section{Participants}

Of 60 eligible and located bereaved families, 41 (68\%) participated in the home visit. Qualitative data were missing from one family due to a tape recording malfunction. Participants $(\mathrm{N}=99)$ included 36 mothers, 24 fathers, and 39 siblings. Mothers averaged 40.50 years of age $(\mathrm{SD}=7.35)$, and $78 \%(\mathrm{n}=28)$ were White. Fathers averaged 43.88 years of age ( $\mathrm{SD}=7.75)$, and $83 \%(\mathrm{n}=20)$ were White. Parent educational level averaged 14.52 years $(S D=2.24)$. Average family socioeconomic status $(M=44.20, S D=25.10)$, using the revised Duncan, ${ }^{36}$ reflected clerical, sales, and service occupations. Siblings were primarily female $(64 \%, \mathrm{n}=25)$, White $(72 \%, \mathrm{n}=28)$, and on average 12.28 years of age $(\mathrm{SD}=2.64)$. Deceased children were mostly male $(54 \%, \mathrm{n}=22)$ and averaged 12 years of age $(\mathrm{SD}=$ $5.27)$ with an average of 2.73 years $(\mathrm{SD}=2.34)$ from diagnosis to death. Data were collected 6 to 19 months $(\mathrm{M}=10.68, \mathrm{SD}=3.48)$ post-death.

\section{Procedures and Measures}

Institutional Review Board approval was obtained at the three participating children's hospitals in the U.S. and Canada. Families were sent an introduction letter from the deceased child's attending physician and were recruited via phone 3 to 12 months post-death. Eligible families (a) had a bereaved sibling 8-17 years old, (b) were fluent in English, and (c) lived within 100 miles of the hospital. Adopted, half-siblings, and step-siblings were eligible if they had regular, ongoing contact with the child who died. Home assessments took place as soon as they could be arranged with families. Informed consent and assent were obtained from each parent and child, respectively. For the larger study, research staff administered a series of questionnaires and semi-structured interviews that were audio-taped for transcription and coding. For this report, individual interviews included an open-ended question developed by the research team. Siblings were asked:

We have talked to many kids/teens who tell us that they have experienced changes as a result of their brother/sister's death; others have identified few changes. Some tell us about negative changes, and some have talked about changes in a positive direction. How would you say you have changed since your brother/sister's death? (If needed, probes included: Personally; in your daily activities; how you get along with family, how you get along with friends/classmates; at school/work; how do you see yourself as the same or different from your friends?)

Parents were asked:

How has (the sibling) changed? (If needed, probes included: what do you see as different about your child - mood, behavior, relationships; at home, at school; with their family, with friends?)

\section{Analysis}

Four researchers independently analyzed data from the open-ended questions through qualitative content analysis. ${ }^{37,}{ }^{38}$ For complete details, refer to Foster et al. ${ }^{39}$ In short, researchers repeatedly read the transcripts to gain a holistic sense of the data. Similar ideas were clustered from 15 transcripts, and preliminary categories emerged. The researchers reviewed the initial coding scheme, extracted quotes, and regularly discussed the rationale for emerging categories. Data were re-examined by recoding original transcripts and making mutually agreed upon category changes. Fifteen new transcripts were added to the coding scheme, and new codes were adopted when data did not fit into an existing category. 
Researchers repeated this process until they reached consensus, and no new categories emerged (i.e., saturation). Sibling transcripts were coded first, followed by parent transcripts.

For the quantitative analysis, two researchers independently counted frequencies of the qualitative themes to compare reports from mothers, fathers, and siblings. Kappa values ranged from 0.92 to 1.00 across themes. McNemar tests examined differences in the frequency of sibling changes between each pair of reports (sibling vs. mother, sibling vs. father, mother vs. father). A Bonferroni-corrected alpha of .017 (.05/3) was used to assess statistical significance within each theme.

\section{Findings}

Three major themes emerged regarding changes in bereaved siblings: (a) personal changes, (b) changes in relationships, and (c) no changes attributed to the death. Frequencies are in Table 1. Comparisons across informants using McNemar tests were not significant. Findings will be presented through descriptions and frequencies of themes reported by mothers, fathers, and siblings.

\section{Personal Changes}

Sixty-eight percent of all participants $(n=68)$ perceived that siblings experienced personal changes since the death including changes in the sibling's: (a) personality, (b) attitude toward and interest in school work, (c) goals and life perspective, and (d) activities and interests.

Changes in personality-Sixty-one percent $(n=22)$ of mothers, $54 \%(n=13)$ of fathers, and $44 \%(\mathrm{n}=17)$ of siblings reported changes in the sibling's personality. These included increased maturity, as well as becoming withdrawn, compassionate, sad, angry, or fearful of another death.

Bereaved siblings developed a greater maturity, as reported by $22 \%(\mathrm{n}=8)$ of mothers, $15 \%$ $(\mathrm{n}=6)$ of siblings, and one father. Siblings said, "I've grown up." A mother said, "She's [14year-old] more mature in some ways than other kids that are her age because of what she's seen." Another mother expressed, "He's [13-year-old] coming more into his own... much more of a voice... more focused."

Some siblings were more withdrawn since the death. Only $5 \%(\mathrm{n}=2)$ of siblings, but $22 \%$ $(\mathrm{n}=8)$ of mothers and $21 \%(\mathrm{n}=5)$ of fathers reported this. An 18-year-old sibling said, "A lot of my friends tell me that I've changed attitude-wise...I'm normally that go-lucky happy person, but lately I've just kinda kept to myself and quiet..." One father reported that his 13year-old is now "a little more withdrawn. She doesn't like to talk about her feelings." A mother shared that her 10-year-old "just prefers to be alone and up in his room."

Only $8 \%(\mathrm{n}=3)$ of mothers and $8 \%(\mathrm{n}=2)$ of fathers reported that siblings were more compassionate, but $23 \%(\mathrm{n}=9)$ of siblings reported this. A 17 -year-old female sibling said, "I've been more aware of people's feelings and more caring towards them, and I'd say more forgiving, giving more second chances." A father perceived that the death changed his daughter's attitude: "She's [11-year-old] very sympathetic towards...kids at school who are disabled... I think it's made her realize that not every child is the same... she likes to help others." One mother shared that her 11-year-old daughter "has changed where she is more loving and caring. She is willing to [do] just about anything it takes to make you happy." 
Fourteen percent $(\mathrm{n}=5)$ of mothers, $13 \%(\mathrm{n}=3)$ of fathers, and $8 \%(\mathrm{n}=3)$ of siblings reported that the sibling's demeanor reflected an overall sadness since the death, such as one sibling who said that there were "more things to be sad about." One father expressed: "I think it was a sobering thing for (15-year-old bereaved sibling)...the reality of (deceased child) passing away really hit her hard. She did a lot of crying. Disturbed her a lot. She's gotten better." A mother shared how her 14-year-old daughter is "not as sweet as she used to be...you can even see sadness in her face."

Several parents ( $19 \%$ of mothers, $n=7 ; 13 \%$ of fathers, $n=3$ ) and one sibling reported that bereaved siblings experienced anger. A father said his 16-year-old son was "Angrier. More given to rage. More willing to express it, the anger. Not in a healthy way.... For the first four to five months, there wasn't a lot of joy. There are bits of joy now, but there's a habit of anger." Similarly, a mother described, "He's [11-year-old] had a couple of little explosions... a couple of holes in his wall...." Another mother said that her 11-year-old "rebels and lashes out against losing her sister."

Two mothers and one sibling described the sibling's fear of experiencing another death in the family. One mother said that "he [8-year-old] feels like something may happen." Another mom expressed: "Experiencing one loss, she's [13-year-old] afraid to do another one. When I got sick here a little while back...it scared her." A 14-year-old sibling said, "I was scared that if one of my parents died, I'd be by myself."

Changes in attitude toward and interest in school work-Twenty-eight percent (n $=10)$ of mothers, $13 \%(\mathrm{n}=3)$ of fathers, and $26 \%(\mathrm{n}=10)$ of siblings reported changes in school work. A 14-year-old said, "I'm doing way better in school than I used to cause...I'm not worrying about spending time with her." One mother reported that her 13-year-old changed schools: "I think it has been better. He's been really happy out there." Siblings also experienced negative changes at school. A 14-year-old said that it was "harder for me to concentrate." A father noted that his 11-year-old "decreased a little bit in his schooling." A mother said there were "phases where school doesn't really mean anything to her [12-yearold]."

Changes in goals and life perspective-Eight percent $(\mathrm{n}=3)$ of mothers, $17 \%(\mathrm{n}=4)$ of fathers, and $21 \%(\mathrm{n}=8)$ of siblings commented on changes in the sibling's priorities. Siblings said they did "not take things for granted" now and were "more appreciative of life." One mother stated, "She [14-year-old] has seen life and death. And a lot of the little stuff is frivolous to her..."A father commented, "She's [17-year-old] always had sort of an interest in biology... She might have gravitated a little bit more towards things that might be more medically related to cancer."

Eight percent $(\mathrm{n}=3)$ of mothers, $8 \%(\mathrm{n}=2)$ of fathers, and $10 \%(\mathrm{n}=4)$ of siblings said that siblings seemed to be motivated by the memory of the deceased brother or sister. One 13year-old boy shared: "I try to kind of be more like him [deceased child]. He always worked really hard.... I work harder at sports and school and everything now." A father said, "Schoolwise it's almost as if he [16-year-old] tried to impress his [deceased] sister. ...He was a terrible student up until high school. It's like he just woke up. All of a sudden he's doing really well." A mother shared that a 12-year-old sibling "really wants to be like (deceased child)."

Changes in activities/interests-The death also changed the sibling's activities or interests as reported by six parents (8\% of mothers, $4 \%$ of fathers) and three siblings (8\%). One 13-year-old said, "I've been getting into more activities.... Going out more because I don't have to stay in and take care of him [deceased sibling] anymore." A mother reported 
that her 10-year-old daughter "does stuff now that she would have never tried before... She's going to play softball this year, and she's never wanted to do anything like that before." Conversely, a few parents noted a loss of interest in activities: "She [14-year-old] is good in art, but then because (deceased child) passed away, she [bereaved sibling] lost that.... She's not interested in doing things, and she even told me that."

\section{Changes in Relationships}

Forty-seven percent $(n=47)$ of participants reported changes in the sibling's relationships. These included: (a) peer relationships, (b) family relationships, and (c) the bereaved sibling's role within the family.

Changes in peer relationships-Fourteen percent $(n=5)$ of mothers, $13 \%(n=3)$ of fathers, and 33\% ( $\mathrm{n}=13)$ of siblings discussed changes in the dynamics of the sibling's friendships, both in terms of how siblings interacted with their existing friends and the deceased child's friends, as well as friendships that were lost/gained or became weaker/ stronger. One mother shared: "She's [12-year-old] more blunt with them [friends]. She tells them how she feels." A 13-year-old sibling said, "I couldn't relate to the kids at school as much.... Friendships sort of changed. I looked at everything everybody said a lot differently." Participants also discussed siblings losing friends, such as this 14-year-old: "Friends, they don't know what to say.... They don't pay attention to you anymore, and you get new friends." A father noted: "For awhile there she [17-year-old] became...engaged [in] (deceased child)'s circle of friends... Then at a certain point....she backed off of that group of friends and migrated to her own friends." Other siblings grew closer to peers after the death: "I've [17-year-old girl] become closer with my best friend. You know, I lost my sister, so I need another girl who I can be close to."

Changes in family relationships-Nineteen percent of mothers $(n=7), 17 \%$ of fathers $(n=4)$, and $23 \%(n=9)$ of siblings reported that the sibling's relationships with family members were closer. In particular, siblings shared: "We talk more," and they receive "more attention from mom and dad." A father reported that his 16-year-old daughter does better now: "We pay attention to each other...we have more time with the family than before." One mother shared that her 9-year-old is "more of a mommy's boy now."

On the other hand, one mother (3\%), one father (4\%), and three siblings (8\%) believed family members had become more distant, such as one 16-year-old who said, "My parents split up." A 13-year-old sibling reflected on his mom: "She comes home, and she's tired. On the days that she's off work, she's got to go to...school and this exercise thing... If you get her to working a little bit, then she doesn't think about it [death of the child] a lot." One mother said that her 9-year-old was "more distant with his father."

Changes in sibling's role in the family-With the absence of the deceased child, siblings were adjusting to a new role in the family as the oldest, youngest, or only child. Twenty-five percent $(\mathrm{n}=9)$ of mothers, $8 \%(\mathrm{n}=2)$ of fathers, and $18 \%(\mathrm{n}=7)$ of siblings discussed this. A 13-year-old sibling shared that it's "awkward, all of a sudden being the only child." A 10-year-old perceived, "The family is short one." A father said, "He's [11year-old] learning to become a big brother." A mother noted, "He [8-year-old bereaved sibling] used to play with him [deceased child], and now he plays alone."

\section{No Changes}

Seventeen percent $(\mathrm{n}=6)$ of mothers, $13 \%(\mathrm{n}=3)$ of fathers, and 15\% $(\mathrm{n}=6)$ of siblings did not report any changes in the sibling. A 10-year-old sibling said, "I don't have any changes... I do usual things, go on the computer, play with my friends." One mother 
reported, "I don't think [17-year-old] has changed a great deal. We think she's still the same outgoing girl... She seems to have a really good perspective...very balanced about it...."

Eleven percent $(n=4)$ of mothers and $8 \%(n=2)$ of fathers perceived that sibling changes were part of normal childhood development. One father said, "I haven't really noticed any negative changes that I associate with (deceased child)'s passing. Coincide more with him (13-year-old bereaved sibling) being a teenager...changes in life... a phase, a stage..." A mother felt similarly: "I don't know if she's depressed. ...being 14-years-old, you're going to be going through some fluctuating moods anyway. So, it's hard to relate what is 14-years-old and what is 14-years-old and seeing your sister suffer. ...I can attribute it to that [development], and not everything that's involved in our family is because of (deceased child)'s illness."

\section{Discussion}

Limited research has examined the frequency and nature of changes experienced by siblings after the death of a brother or sister from cancer. This study used multiple informants and qualitative and quantitative analyses to identify and assess the frequency of changes in siblings on average within the first year of a child's death. The majority of family members perceived that siblings did experience changes after the death including personal changes and changes in relationships. This is consistent with studies which also found that bereaved siblings experienced a range of positive and negative personal and relationship changes. ${ }^{11-13,19-21,27-29,40}$ However, change was not universal.

Participants most frequently reported personal changes in bereaved siblings, particularly personality changes. Differences, while statistically non-significant, were noted across informants. Siblings were more likely to report positive personal changes that may reflect growth and adaptation; parents were more likely to report negative changes that may reflect a continuum of normal sadness and longing for the deceased or difficulties adapting to the death. Greater maturity was the most common personal change according to siblings, and more than twice as many siblings relative to moms or dads reported changes in compassion and life priorities. Siblings less often than mothers or fathers reported negative changes such as being sad, angry, withdrawn, or fearful of experiencing another death. However, within the subdomains of personality changes, we found fairly equal positive changes (e.g., maturity, compassion), and negative changes (e.g., sad, withdrawn, anger). The majority of participants reported either positive or negative changes in siblings' personality, rather than both positive and negative. Consistent with previous literature, some siblings reported or were reported to develop a greater maturity and more prosocial behaviors, ${ }^{12}$ while others reported negative consequences such as guilt, anger, anxiety, sadness, and longing for the deceased, ${ }^{\text {e.g., }}$ 12, 14, 28 The range of personality changes reported about bereaved siblings represents a new finding which may reflect diversity in individual personalities and past experiences. More work is needed to elucidate the sources of these differences.

A new finding emerged indicating that bereaved siblings were motivated by their deceased brothers or sisters. This finding was unique, as siblings' motivation seemed to stem from an internal desire to be more like their deceased brothers or sisters. In our previous work, we found a similar theme in which bereaved parents and siblings reported being inspired to live life differently because of the deceased child; however, the inspiration originated in the advice given by the ill children prior to their deaths; ${ }^{39}$ we also found that some bereaved parents and siblings participated in activities to memorialize or honor the legacies of deceased children. These reports tended to reflect strategies to continue bonds with the deceased child. ${ }^{41}$ More work is needed to explore how or why some bereaved siblings seem 
to be motivated by their deceased siblings and possible associations with grief and adjustment.

About half of participants cited changes in sibling relationships, most often with peers. Siblings reported these changes more frequently than parents. Thus, parents may not be as attuned to the effects on important social relationships relative to observable changes in the sibling's personality or emotional well-being. Some siblings developed new relationships and stronger bonds with current friends, while others ended relationships or felt more distant from friends. This is consistent with previous literature suggesting that bereaved siblings experience gradual changes in their social network over time. ${ }^{19}$ Some siblings experience feelings of social isolation and withdrawal, ${ }^{23,33}$ while others experience the reemergence of friendships after the death. ${ }^{14}$

Some participants noted feeling closer to family members after the death, while reports of more distant family relationships were rare. This could be explained in part by bereaved siblings and parents sharing the intimate experience of the death and therefore leaning on each other for support. Mothers have been most commonly identified as helpful to bereaved siblings in previous work. ${ }^{12}$ Siblings have also been reportedly closer to family members in part from feeling protective of and responsible for caring for their grieving parents, ${ }^{12}, 19$ yet we did not find evidence of this in our study.

This is the first study we could identify to examine changes in siblings after the death of a brother or sister to cancer from three different perspectives: mothers, fathers and siblings. This relatively uncommon approach allowed us to address commonalities of family perspectives as well as unique contributions. In general, there was consistency across informants regarding perceived changes in the siblings. While none of our quantitative comparisons among mothers, fathers, or siblings were statistically significant, we had limited power for these analyses. The actual percentage of themes suggests both similarities and differences across informants that warrant further investigation. Our findings suggest that the assessment of sibling grief responses should involve direct communication not only with parents, but also with siblings. Discrepancies between parent proxy and child report of internalizing behavior have been reported previously with pediatric brain tumor survivors, ${ }^{43}$ other clinical samples, ${ }^{44}$ and healthy children. ${ }^{45}$ Obtaining child self-report and parent proxy reports provides different perspectives important for making clinical treatment decisions and measuring research outcomes. 46,47

Our study also supports the importance of collecting and reporting qualitative frequency data. Many qualitative studies e.g., 39 use verbal counting ${ }^{48}$ and terms such as some, many, or most to represent numbers of respondents linked to thematic codes. Such terms are not welldefined $^{49}$ and can be easily misinterpreted. Counting and use of numbers in qualitative work is essential to the analytic process and recognition of patterns. ${ }^{48}$ Frequency data can be reported as the presence of a theme for each participant, as in our study, or as the intensity of a theme (e.g., number of times each code is present ${ }^{50}$ ). Frequency counts can provide vital information for comparing qualitative categories or reports from multiple informants and better inform other researchers conducting mixed research synthesis. ${ }^{49}$

\section{Limitations}

Our findings should be considered in the context of several limitations. Findings may not generalize to all bereaved siblings as our participants were primarily White, Englishspeaking, and included families whose children died of cancer. Data were cross-sectional, and reports of sibling changes may not persist over time. The interview question was at the end of a long assessment (e.g., 2 to 2.5 hours), and participants may have been less talkative due to fatigue. Parental anxiety related to the wellness of the surviving child may have 
impacted parent reports. Despite these limitations, this study addressed a gap in the literature by examining changes in siblings as reported by bereaved mothers, fathers, and siblings relatively soon after the death. Other strengths included multiple data collection sites, good recruitment rates that minimized ascertainment bias, and both qualitative and quantitative analyses.

\section{Implications for Future Research}

More research is needed to further our understanding of sibling grief in response to childhood cancer death. Future research could include longitudinal studies to examine quantitative and qualitative reports of changes in siblings over time, as well as how parents' own grief and adjustment affects mother and father proxy report. Studies examining predictors of change (e.g., demographic factors, characteristics of the illness and death, or other individual and family factors) in bereaved siblings are necessary to inform the design and evaluation of interventions to promote healthy adaptation.

\section{Implications for Practice}

Nurses and other clinicians may encourage families to discuss possible changes that siblings can experience after the death of a sibling. Parents may worry about potential effects on healthy siblings very early in the cancer illness trajectory and through bereavement, if the child with cancer dies. Families may benefit from knowing the positive nature of siblings' reports and by the hope offered by siblings who adapt to the death of a brother or sister. Families may also benefit from knowing that the death of a brother or sister is profound for some siblings. Some parents may anticipate that their bereaved children will experience changes and become concerned if changes seem unapparent. Nurses and other clinicians can provide reassurance that change may not be universal to all bereaved siblings. Families can gain a sense of normalcy knowing that the range of positive and negative responses is part of the human condition.

In conclusion, findings from this study contribute to our current knowledge of sibling bereavement and suggest directions for further research. To love is to grieve - and sibling grief can be manifested in many ways. Provider education on the range of sibling grief responses could equip nurses and clinicians to better prepare families for and guide families during bereavement. More work is needed to continue advancing the science of sibling bereavement related to cancer so that nurses can provide optimal care to children with cancer and their families, from the time of diagnosis, to cure or end of life, and thereafter.

\section{Acknowledgments}

The authors would like to thank the families who generously participated in this work. This research was supported by a grant from the National Institutes of Health (R01 CA98217) to Cynthia Gerhardt.

\section{References}

1. Kreider, RM. Living arrangements of children: 2004. U.S. Census Bureau; Washington, DC: 2007. p. 70-114.

2. Heron M. Deaths: Leading causes for 2004. Natl Vital Stat Rep. 2007; 56(5):1-95. [PubMed: 18092547]

3. Statistics Canada Summary Tables. Statistics Canada Web site. http://www40.statcan.ca/101/cst01/. Accessed March 28, 2011

4. Davies, B. Long-term effects of sibling death in childhood. In: Adams, DW.; Deveau, EJ., editors. Beyond the innocence of childhood: Helping children and adolescents cope with death and bereavement. Baywood Publishing; Amityville, NY: 1995. p. 89-98. 
5. Davies, B. Shadows in the sun: The experiences of sibling bereavement in childhood. Brunner/ Mazel; Philadelphia, PA: 1999.

6. Packman W, Horsley H, Davies B, Kramer R. Sibling bereavement and continuing bonds. Death Stud. 2006; 30(9):817-841. [PubMed: 17004367]

7. Stormshak EA, Bullock BM, Falkenstein CA. Harnessing the power of sibling relationships as a tool for optimizing social-emotional development. New Dir Child Adolesc Dev. 2009; 2009(126):6177. [PubMed: 19960535]

8. Wong TML, Branje SJT, VanderValk IE, Hawk ST, Meeus WHJ. The role of siblings in identity development in adolescence and emerging adulthood. J Adolesc. 2010; 33(5):673-682. [PubMed: 19954830]

9. Davies, B. The grief of siblings. In: Webb, NB., editor. Helping bereaved children: A handbook for practitioners. Guilford Press; New York: 2002.

10. Stroebe M, Schut H. The dual process model of coping with bereavement: Rationale and description. Death Studies. 1999; 23:197-224. [PubMed: 10848151]

11. Hutton CJ, Bradley BS. Effects of sudden infant death on bereaved siblings: A comparative study. J Child Psychol Psychiatry. 1994; 35(4):723-732. [PubMed: 8040224]

12. Mahon MM, Page ML. Childhood bereavement after the death of a sibling. Holist Nurs Pract. 1995; 9(3):15-26. [PubMed: 7721965]

13. McCown DE, Davies B. Patterns of grief in young children following the death of a sibling. Death Stud. 1995; 19(1):41-53.

14. Nolbris M, Hellstrom AL. Siblings' needs and issues when a brother or sister dies of cancer. J Pediatr Oncol Nurs. 2005; 22(4):227-233. [PubMed: 15994341]

15. Fanos JH, Nickerson BG. Long-term effects of sibling death during adolescence. J Adol Res. 1991; 6(1):70-82.

16. Rosen H. Prohibitions against mourning in childhood sibling loss. Omega J Death Dying. 1985; 15(4):307-316.

17. Applebaum DR, BG B. Unexpected childhood death: Post-traumatic stress disorder in surviving siblings and parents. J Clin Child Psychol. 1991:20114-120.

18. Powell M. The psychosocial impact of sudden infant death syndrome on siblings. Irish J Psychol. $1991 ; 12: 235-247$.

19. Dyregrov K, Dyregrov A. Siblings after suicide- "The forgotten bereaved.”. Suicide Life Threat. 2005; 35(6):714-724.

20. Hogan NS, DeSantis L. Things that help and hinder adolescent sibling bereavement. West J Nurs Res. 1994; 16(2):132-153. [PubMed: 8203135]

21. Hogan NS, Greenfield DB. Adolescent sibling bereavement symptomatology in a large community sample. J Adol Res. 1991; 6(1):97-112. DOI: 10.1177/074355489161008.

22. Birenbaum L, Robinson M, Phillips D, Stewart B, McCown D. The response of children to the dying and death of a sibling. Omega J Death Dying. 1989; 20(3):213-228.

23. Davies B. Long-term outcomes of adolescent sibling bereavement. J Adol Res. 1991:683-96.

24. Martinson IM, Campos RG. Adolescent bereavement: Long-term responses to a sibling's death from cancer. J Adol Res. 1991; 6:54-69.

25. deCinque N, Monterosso N, Dadd L, Sidhu G, Macpherson R, Aoun S. Bereavement support for families following the death of a child from cancer: Experience of bereaved parents. J Psychosoc Oncol. 2006; 24(2):65-84. [PubMed: 17046807]

26. Woodgate RL. Siblings' experiences with childhood cancer: A different way of being in the family. Cancer Nurs. 2006; 29(5):406-414. [PubMed: 17006115]

27. Batten M, Oltjenbruns KA. Adolescent sibling bereavement as a catalyst for spiritual development: A model for understanding. Death Stud. 1999; 23(6):529-546. [PubMed: 10558613]

28. Fanos JH, Little GA, Edwards WH. Candles in the snow: Ritual and memory for siblings of infants who died in the intensive care nursery. Journal Pediatr. 2009; 154(6):849-853.

29. Silverman PR, Baker J, Cait CA, Boerner K. The effects of negative legacies on the adjustment of parentally bereaved children and adolescents. Omega J Death Dying. 2003; 46:335-352. 
30. Finke LM, Birenbaum LK, Chand N. Two weeks post-death report by parents of siblings' grieving experience. J Child Adol Psych Nurs. 1994; 7(4):17-25.

31. Erlandsson K, Avelin P, Säflund K, Wredling R, Rådestad I. Siblings' farewell to a stillborn sister or brother and parents' support to their older children: A questionnaire study from the parents' perspective. J Child Health Care. 2010; 14(2):151-160. [PubMed: 20200194]

32. Horsley H, Patterson T. The effects of a parent guidance intervention on communication among adolescents who have experienced the sudden death of a sibling. Am J Fam Ther. 2006; 34(2): 119-137.

33. Martinson IM, Campos RG. Adolescent bereavement: Long-term response to a sibling's death from cancer. J Adol Res. 1991; 6(1):54-69.

34. Packman W, Mazaheri M, Sporri L, Long JK, Chesterman B, Fine J, et al. Projective drawings as measures of psychosocial functioning in siblings of pediatric cancer patients from the camp okizu study. J Pediatr Oncol Nurs. 2008; 25(1):44-55. [PubMed: 18187600]

35. Birenbaum LK. Assessing children's and teenagers' bereavement when a sibling dies from cancer: A secondary analysis. Child Care Health Dev. 2000; 26(5):381-400. [PubMed: 10998002]

36. Nakao, K.; Treas, J. The socioeconomic index of occupations: Construction from the 1989 occupational prestige scores. University of Chicago, National Opinion Research Center; Chicago, IL: 1992.

37. Hickey G, Kipping C. A multi-stage approach to the coding of data from open-ended questions. Nurse Res. 1996; 4(1):81-91.

38. LoBiondo-Wood, G.; Haber, J. Nursing research: Methods and critical appraisal for evidencebased practice. 6th ed.. Mosby Elsevier; St. Louis, MO: 2006.

39. Foster TL, Gilmer MJ, Davies B, Barrera M, Fairclough D, Vannatta K, et al. Bereaved parents' and siblings' reports of legacies created by children with cancer. J Pediatr Oncol Nurs. 2009; 26(6):369-376. [PubMed: 20032298]

40. Sood A, Razdan A, Weller E, Weller R. Children's reactions to parental and sibling death. Curr Psychiatry Rep. 2006; 8(2):115-120. [PubMed: 16539886]

41. Foster TL, Gilmer MJ, Davies B, Dietrich M, Barrera M, Fairclough DL, Vannatta K, Gerhardt CA. Comparison of continuing bonds reported by parents and siblings after a child's death from cancer. Death Stud. 2011 In press.

42. Adler A. Characteristics of the first, second, and third child. Children. 1928; 3:14-52.

43. Schulte F, Bartels U, Bouffet E, Janzen L, Hamilton J, Barrera M. Body weight, social competence, and cognitive functioning in survivors of childhood brain tumors. Pediatr Blood Cancer. 2010; 55(3):532-539. [PubMed: 20658626]

44. Owens J, Goldfine M, Evangelista N, Hoza B, Kaiser N. A critical review of self-perceptions and the positive illusory bias in children with adhd. Clin Child Fam Psychol Rev. 2007; 10(4):335351. [PubMed: 17902055]

45. Cremeens J, Eiser C, Blades M. Factors influencing agreement between child self-report and parent proxy-reports on the pediatric quality of life inventory 4.0 (PedsQL) generic core scales. Health Qual Life Outcomes. 2006; 4:58. [PubMed: 16942613]

46. Baca CB, Vickrey BG, Hays RD, Vassar SD, Berg AT. Differences in child versus parent reports of the child's health-related quality of life in children with epilepsy and healthy siblings. Value Health. 2010; 13(6):778-786. [PubMed: 20561342]

47. Jokovic A, Locker D, Guyatt G. How well do parents know their children? Implications for proxy reporting of child health-related quality of life. Qual Life Res. 2004; 13(7):1297-1307. [PubMed: 15473508]

48. Sandelowski M. Real qualitative researchers do not count: The use of numbers in qualitative research. Res Nurs Health. 2001; 24(3):230-240. [PubMed: 11526621]

49. Chang Y, Voils CI, Sandelowski M, Hasselblad V, Crandell JL. Transforming verbal counts in reports of qualitative descriptive studies into numbers. West J Nurs Res. 2009; 31(7):837-852. [PubMed: 19448052]

50. Hinds PS, Oakes LL, Hicks J, Powell B, Srivastava DK, Spunt SL, et al. "Trying to be a good parent" as defined by interviews with parents who made phase I, terminal care, and resuscitation decisions for their children. J Clin Oncol. 2009; 27(35):5979-5985. [PubMed: 19805693] 
Table 1

Frequency of Participants Reporting Changes in Bereaved Siblings ${ }^{a}$

\begin{tabular}{|c|c|c|c|c|}
\hline & All Participants (N=99) & Siblings $(n=39)$ & Moms (n=36) & Dads $(n=24)$ \\
\hline Personal changes & $68(69 \%)$ & $27(69 \%)$ & $25(69 \%)$ & $16(67 \%)$ \\
\hline Personality & $52(53 \%)$ & $17(44 \%)$ & $22(61 \%)$ & $13(54 \%)$ \\
\hline Maturity & $15(15 \%)$ & $6(15 \%)$ & $8(22 \%)$ & $1(4 \%)$ \\
\hline Withdrawn & $15(15 \%)$ & $2(5 \%)$ & $8(22 \%)$ & $5(21 \%)$ \\
\hline Compassion & $14(14 \%)$ & $9(23 \%)$ & $3(8 \%)$ & $2(8 \%)$ \\
\hline Sadness & $11(11 \%)$ & $3(8 \%)$ & $5(14 \%)$ & $3(13 \%)$ \\
\hline Anger & $11(11 \%)$ & $1(3 \%)$ & $7(19 \%)$ & $3(13 \%)$ \\
\hline Fear of another death & $3(3 \%)$ & $1(3 \%)$ & $2(6 \%)$ & $0(0 \%)$ \\
\hline School work & $23(23 \%)$ & $10(26 \%)$ & $10(28 \%)$ & $3(13 \%)$ \\
\hline Goals/ life perspective & $21(21 \%)$ & $10(26 \%)$ & $5(14 \%)$ & $6(25 \%)$ \\
\hline Life priorities & $15(15 \%)$ & $8(21 \%)$ & $3(8 \%)$ & $4(17 \%)$ \\
\hline Motivated by deceased sib & $9(9 \%)$ & $4(10 \%)$ & $3(8 \%)$ & $2(8 \%)$ \\
\hline Activities/interests & $7(7 \%)$ & $3(8 \%)$ & $3(8 \%)$ & $1(4 \%)$ \\
\hline Changes in relationships & $47(47 \%)$ & $22(56 \%)$ & $17(47 \%)$ & $8(33 \%)$ \\
\hline Peers & $21(21 \%)$ & $13(33 \%)$ & $5(14 \%)$ & $3(13 \%)$ \\
\hline Family relationships closer & $20(20 \%)$ & $9(23 \%)$ & $7(19 \%)$ & $4(17 \%)$ \\
\hline Sibling role change & $18(18 \%)$ & $7(18 \%)$ & $9(25 \%)$ & $2(8 \%)$ \\
\hline Family relationships more distant & $5(5 \%)$ & $3(8 \%)$ & $1(3 \%)$ & $1(4 \%)$ \\
\hline No changes attributed to death & $21(21 \%)$ & $6(15 \%)$ & $10(28 \%)$ & $5(21 \%)$ \\
\hline No changes & $15(15 \%)$ & $6(15 \%)$ & $6(17 \%)$ & $3(13 \%)$ \\
\hline Changes attributed to development & $6(6 \%)$ & $0(0 \%)$ & $4(11 \%)$ & $2(8 \%)$ \\
\hline
\end{tabular}

${ }^{a}$ Differences were not statistically significant using a Bonferroni-corrected alpha, $p>.017$ 